\title{
Curcumin inhibits the growth of liver cancer stem cells through the phosphatidylinositol 3-kinase/protein kinase B/mammalian target of rapamycin signaling pathway
}

\author{
JI WANG, CHUNYING WANG and GAOFENG BU \\ Department of Liver Disease, Xuzhou Infectious Disease Hospital, Xuzhou, Jiangsu 221004, P.R. China
}

Received May 29, 2017; Accepted August 23, 2017

DOI: $10.3892 /$ etm.2018.5805

\begin{abstract}
Cancer stem cells are considered as a main cause of cancer recurrence. In the present study, the effects of curcumin on the growth of liver cancer stem cells (LCSCs) were investigated. The proliferation and apoptosis of LCSCs were assessed by MTT assays and flow cytometry. Changes in the expression of apoptosis-related proteins were identified by western blotting. The results of the study demonstrated that curcumin treatment inhibited the growth of LCSCs, induced cell apoptosis, as well as regulated the expression of apoptosis-associated proteins and the release of cytochrome $c$. Further experiments revealed that treatment with curcumin inhibited that the activation of the phosphatidylinositol 3-kinase (PI3K)/protein kinase $B$ $(\mathrm{AKT}) /$ mammalian target of rapamycin (mTOR) signaling pathway. Treatment with an activator of PI3K/AKT reversed the curcumin-induced growth inhibition of LCSCs. These results demonstrated that curcumin inhibited the growth of LCSCs through the PI3K/AKT/mTOR signaling pathway. Thus, the present study suggested that curcumin may be a potentially efficient agent in the treatment of liver cancer.
\end{abstract}

\section{Introduction}

Liver cancer is one of the most common malignancies worldwide, with $\sim 600,000$ new cases diagnosed annually (1). However, the 5-year survival rate of liver cancer is <9\% (2). This tumor is the fourth cause of cancer-associated mortality, ranking second in men and sixth in women, with $>250,000$ mortalities annually $(1,3-5)$. At present, surgical resection is the major therapeutic strategy for liver cancer, although a high rate of recurrence remains $(6,7)$.

Stem cells are a type of cells harboring the ability to self-renew and differentiate (8). Cancer stem cells are a subset

Correspondence to: Dr Gaofeng Bu, Department of Liver Disease, Xuzhou Infectious Disease Hospital, 63 Shuangyong Road, Xuzhou, Jiangsu 221004, P.R. China

E-mail: bu1123xuzhou@163.com

Key words: apoptosis, curcumin, liver cancer, phosphatidylinositol 3-kinase, protein kinase B, mammalian target of rapamycin, stem cells of cancer cells with stem cell properties. Although radiotherapy and chemotherapy can eliminate the majority of tumor cells, cancer stem cells have the ability to self-renew and differentiate to generate tumor cell heterogeneity, and thus resist these therapies (9). Liver cancer stem cells (LCSCs) are considered to account for the chemotherapy resistance and recurrence of liver cancer $(10,11)$. Multiple signals pathways, including Notch and Wnt/ $\beta$-catenin, are found to serve important roles in the stemness of LCSCs (12). The regulation of LCSCs via the manipulation of internal signaling pathways may become a feasible treatment for patients with liver cancer.

Curcumin is a yellow natural compound derived from Rhizoma curcumae longae and is widely used as a spice in Asia. Curcumin has been demonstrated to exert anti-inflammatory, antioxidant and antiangiogenic effects (13-15), while it also exerts a potential antitumor effect (15-17). However, the effects of curcumin on LCSCs remain unclear. Therefore, the aim of the present study was to examine the effects of curcumin on the growth of LCSCs, as well as the underlying mechanism of its action. The study demonstrated that treatment with curcumin is able to inhibit the growth of LCSCs, and this compound may be a promising treatment agent for liver cancer.

\section{Materials and methods}

Cell culture. The human liver cancer cell line HepG2 was obtained from the American Type Culture Collection (Manassas, VA, USA). The cells were grown in Dulbecco's modified Eagle's medium (DMEM; Gibco; Thermo Fisher Scientific, Inc., Waltham, MA, USA) supplemented with $10 \%$ fetal bovine serum (FBS; Hyclone; GE Healthcare Life Sciences, Logan, UT, USA), and cultured in a humidified atmosphere at $37^{\circ} \mathrm{C}$ with $5 \% \mathrm{CO}_{2}$.

Isolation of LCSCs by magnetic activated cell sorting (MACS). CD133 is a marker of stem cells (18), and thus the present study used a CD133 MicroBead kit (MiltenyiBiotec $\mathrm{GmbH}$, Bergisch Gladbach, Germany) for the isolation of LCSCs. Briefly, HepG2 cells were digested with trypsin, washed with phosphate-buffered saline (PBS) and made into a single-cell suspension. The cells were then centrifuged at $300 \mathrm{x} \mathrm{g}$ for $10 \mathrm{~min}$ at $4^{\circ} \mathrm{C}$, and $1 \times 10^{7}$ cells were resuspended in $60 \mu \mathrm{l}$ buffer. Next, $20 \mu \mathrm{l} \mathrm{FcR}$ blocking reagent and $20 \mu \mathrm{l}$ 
CD133 MicroBeads supplied in the kit were added into the cells and incubated at $4^{\circ} \mathrm{C}$ for $15 \mathrm{~min}$. Subsequent to washing with buffer, the cells were centrifuged at $300 \mathrm{x} \mathrm{g}$ for $10 \mathrm{~min}$ at $4^{\circ} \mathrm{C}$, and then added into an appropriate MACS column that was placed in the magnetic field of a MACS separator (both MiltenyiBiotec $\mathrm{GmbH}$ ). When the column reservoir was empty, the column was washed with $500 \mu 1$ buffer, removed from the separator and eluted with an $1 \mathrm{ml}$ buffer. The isolated cells were grown in DMEM with $10 \%$ FBS and cultured in a humidified atmosphere at $37^{\circ} \mathrm{C}$ with $5 \% \mathrm{CO}_{2}$.

MTT assay for cell viability determination. The LCSCs were seeded into 96-well plates with 3,000 cells in each well. At $24 \mathrm{~h}$ later, the cells were treated with $0,10,20,40$ or $80 \mu \mathrm{M}$ curcumin (Sigma-Aldrich; Merck KGaA, Darmstadt, Germany) at $37^{\circ} \mathrm{C}$ for $24 \mathrm{~h}$, and then the cell viability was assessed by MTT assay. Briefly, MTT reagent (Sigma-Aldrich; Merck KGaA) at a final concentration of $0.5 \mathrm{mg} / \mathrm{ml}$ was added into each well and incubated for an additional $4 \mathrm{~h}$. Subsequently, the media were removed, and $200 \mu \mathrm{l}$ dimethyl sulfoxide (Sigma-Aldrich; Merck KGaA) was added into each well. The absorbance at $570 \mathrm{~nm}$ was then measured by a microplate reader (Bio-Rad Laboratories, Inc., Hercules, CA, USA).

Apoptosis detection. The LCSCs were seeded into 6-well plates at a density of $1 \times 10^{5}$ cells in each well and treated with 0 or $20 \mu \mathrm{M}$ curcumin at $37^{\circ} \mathrm{C}$ for $24 \mathrm{~h}$. Next, the cell apoptosis was detected by flow cytometry with a cell apoptosis detection kit (Nanjing KeyGen Biotech Co., Ltd., Nanjing, China). Briefly, the cells were collected, washed twice with PBS and then resuspended in $500 \mu \mathrm{l}$ binding buffer. Subsequently, $5 \mu \mathrm{l}$ Annexin V-fluorescein isothiocyanate and $5 \mu \mathrm{l}$ propidium iodide were added into the cells and incubated for an additional $15 \mathrm{~min}$. The cell apoptosis was then analyzed by flow cytometry.

Western blot analysis. The LCSCs were seeded into 6-well plates $\left(1 \times 10^{5}\right.$ cells/well $)$ and treated with 0 or $20 \mu \mathrm{M}$ curcumin at $37^{\circ} \mathrm{C}$ for $24 \mathrm{~h}$. Then the cells were collected by centrifugation (speed, $300 \mathrm{x} \mathrm{g}$ ) at $4^{\circ} \mathrm{C}$ for $10 \mathrm{~min}$. Total proteins in the cells from each group were extracted using radioimmunoprecipitation assay lysis buffer (Beyotime Institute of Biotechnology, Haimen, China) with $1 \%$ phenylmethanesulfonyl fluoride (Beyotime Institute of Biotechnology). The mitochondrial and cytoplasmic proteins were extracted using a cell mitochondria isolation kit (Beyotime Institute of Biotechnology). Subsequent to measuring the concentration of proteins with a BCA protein assay kit (Beyotime Institute of Biotechnology), $40 \mu \mathrm{g}$ proteins from each group were separated by $12 \%$ SDS-PAGE. Next, the separated proteins were transferred onto a polyvinylidene fluoride membranes (EMD Millipore, Bedford, MA, USA). After blocking with $5 \%$ skim milk, the membranes were incubated at $4^{\circ} \mathrm{C}$ overnight with primary antibodies against caspase- 3 (1:500; cat. no. ab44976; Abcam, Cambridge, UK), caspase-9 (1:1,000; cat. no. ab25758; Abcam), B-cell lymphoma-2 (Bcl-2; 1:1,000; cat. no. 4223; Cell Signaling Technology, Inc., Danvers, MA, USA), Bcl-2 associated X protein (Bax; 1:1,000; cat. no. 5023; Cell Signaling Technology), cytochrome $c$ (1:200; cat. no. sc-8385; Santa Cruz Biotechnology,
Inc., Dallas, TX, USA), phosphatidylinositol 3-kinase (PI3K; 1:200; cat. no. sc-293172; Santa Cruz Biotechnology, Inc.), protein kinase B (AKT; 1:200; cat. no. sc-55523; Santa Cruz Biotechnology, Inc.), phosphorylated AKT (p-AKT; 1:1,000; cat. no. 4051; Cell Signaling Technology, Inc.), mammalian target of rapamycin (mTOR; 1:200; cat. no. sc-8319; Santa Cruz Biotechnology, Inc.), p-mTOR (1:200; cat. no. sc-101738; Santa Cruz Biotechnology, Inc.), cytochrome $c$ oxidase subunit IV (1:1,000; cat. no. 11242-1-AP; ProteinTech Group, Inc., Chicago, IL, USA), serving as internal reference for mitochondrial proteins) and $\beta$-actin (1:1,000; cat. no. AF0003; Beyotime Institute of Biotechnology), which served as the internal reference for total proteins. Following washing with Tris-buffered saline with Tween 20, the membranes were incubated with the corresponding horseradish peroxidase-conjugated secondary antibodies (cat. no. A0181, A0216, A0208; all 1:1,000; Beyotime Institute of Biotechnology) at $37^{\circ} \mathrm{C}$ for $2 \mathrm{~h}$. Finally, the membranes were visualized with an enhanced chemiluminescence detection system (Beyotime Institute of Biotechnology). The protein levels were quantified using Quantity One software (version 4.6; Bio-Rad Laboratories, Inc.).

Treatment with PI3K/AKT signal activator, 740Y-P. LCSCs were seeded into 6 -well plates $\left(1 \times 10^{5}\right.$ cells/well $)$ and treated with $20 \mu \mathrm{M}$ curcumin for $24 \mathrm{~h}$. Next, $20 \mu \mathrm{M}$ 740Y-P (R\&D Systems, Inc., Minneapolis, MN, USA) was added into cells and incubated for a further $1 \mathrm{~h}$. The cells were then collected and subjected to MTT assay, apoptosis detection and western blot analysis, as described earlier.

Statistical analysis. All experiments were repeated more than three times and the results are presented as the mean \pm standard deviation. Differences between each group were analyzed using Student's t-test in GraphPad Prism 5.0 (GraphPad Software, Inc., La Jolla, CA, USA). $\mathrm{P}<0.05$ was considered to indicate a statistically significant difference.

\section{Results}

Curcumin inhibits the proliferation of LCSCs. Following isolation, the LCSCs were treated with different concentrations of curcumin, and then an MTT assay was used to detect the proliferation of LCSCs. As shown in Fig. 1, following treatment with $10,20,40$ or $80 \mu \mathrm{M}$ curcumin, the proliferation of LCSCs was significantly decreased compared with that in the untreated control group $(\mathrm{P}<0.05)$. These results demonstrated that curcumin treatment markedly inhibited the proliferation of LCSCs. In addition, compared with the $10 \mu \mathrm{M}$ curcumin group, treatment with $20 \mu \mathrm{M}$ curcumin further decreased the proliferation of LCSCs $(\mathrm{P}<0.01)$. However, LCSCs treated with 40 or $80 \mu \mathrm{M}$ curcumin demonstrated no significant difference when compared with LCSCs treated with $20 \mu \mathrm{M}$ curcumin. Thus, the concentration of $20 \mu \mathrm{M}$ curcumin was used in the subsequent experiments.

Curcumin induces the apoptosis of LCSCs. Subsequent to treatment with curcumin, the cell apoptosis was detected by flow cytometry. As shown in Fig. 2, the percentage of apoptotic cells in the control group was $1.23 \pm 0.35 \%$. However, following 


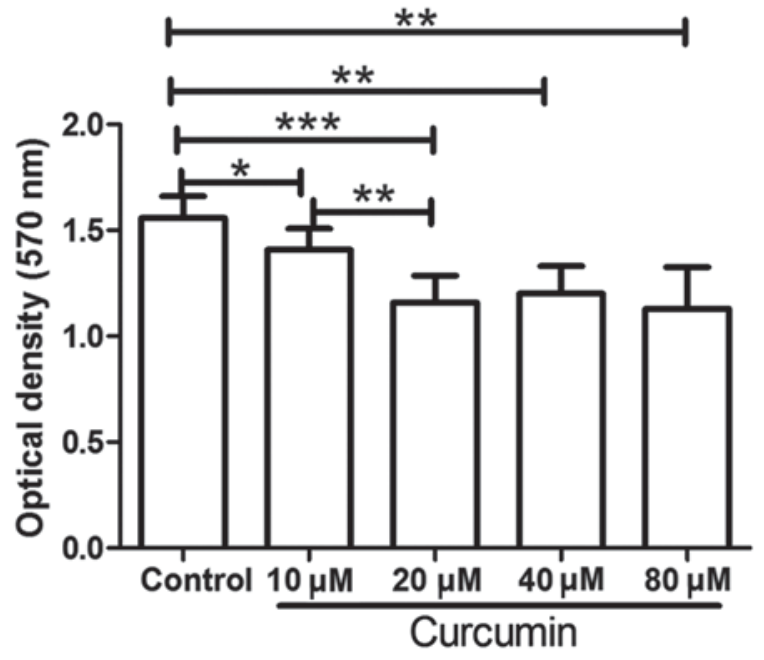

Figure 1. Curcumin inhibited the proliferation of LCSCs. Following treatment with $0-80 \mu \mathrm{M}$ curcumin, the proliferation of LCSCs was assessed by MTT assay. Each experiment was repeated more than three times. The results are presented as the mean \pm standard deviation. ${ }^{*} \mathrm{P}<0.05,{ }^{* *} \mathrm{P}<0.01$ and ${ }^{* * *} \mathrm{P}<0.001$. LCSCs, liver cancer stem cells

treatment with $20 \mu \mathrm{M}$ curcumin, the percentage of apoptotic cells was increased to $11.37 \pm 1.04 \%$, which was significantly higher in comparison with that in the control group $(\mathrm{P}<0.001)$. These results demonstrated that treatment with curcumin induced the apoptosis of LCSCs.

To further examine the cell apoptosis, the protein levels of caspase- 3 and caspase-9 in the LCSCs were also detected by western blot analysis. Following treatment with curcumin, the relative protein levels of caspase-3 were markedly increased from $0.09 \pm 0.02$ in the control to $0.22 \pm 0.03$ in the treated cells (Fig. 3A; P<0.01). Similarly, the protein levels of caspase-9 were significantly increased from $0.19 \pm 0.03$ in the control cells to $0.62 \pm 0.03$ in the curcumin-treated cells (Fig. 3B; $\mathrm{P}<0.001$ ). The levels of apoptosis-associated proteins Bax and Bcl-2 were also detected in the present study. The results indicated that the protein levels of Bax were evidently increased from $0.23 \pm 0.03$ to $1.08 \pm 0.13$ (Fig. $3 \mathrm{C}$; $\mathrm{P}<0.001$ ), whereas the protein levels of Bcl-2 were decreased from $1.21 \pm 0.09$ to $0.84 \pm 0.08$ (Fig. 3D; $\mathrm{P}<0.01)$ in the control and curcumin-treated cells, respectively. Furthermore, the release of cytochrome $c$ from mitochondria was assessed by western blot analysis. As shown in Fig. 4A and $\mathrm{B}$, the levels of cytochrome $c$ in the mitochondria were decreased from $0.95 \pm 0.08$ in the control cells to $0.52 \pm 0.08$ in the curcumin-treated cells $(\mathrm{P}<0.01)$, whereas the levels of cytochrome $c$ in the cytoplasm were increased from $0.27 \pm 0.05$ to $0.82 \pm 0.06(\mathrm{P}<0.001)$. These results provided additional evidence for the apoptosis-induced effects of curcumin.

Curcumin inhibits the activation of the PI3K/AKT/mTOR signaling pathway. Following treatment with curcumin, the protein expression levels of PI3K were detected by western blot analysis. As shown in Fig. 5A, the protein levels of PI3K were significantly decreased upon curcumin treatment $(\mathrm{P}<0.01)$. The phosphorylation of AKT and mTOR was also detected by western blot analysis. The results revealed that the protein levels of p-AKT were significantly decreased after treatment with curcumin $(\mathrm{P}<0.001)$, whereas the protein levels of AKT showed no significant changes (Fig. 5B). There was also a marked decrease in the protein levels of p-mTOR $(\mathrm{P}<0.01)$, with no evident alteration observed in the protein levels of mTOR (Fig. 5C). These results demonstrated that the activation of PI3K/AKT/mTOR signaling pathway was inhibited by curcumin.

PI3K/AKT activator 740Y-P reverses the effects of curcumin. Following treatment with curcumin and/or 740Y-P, an activator of PI3K/AKT signaling, the cell viability of LCSCs was detected by MTT assay. The results of MTT assay revealed that curcumin inhibited the proliferation of LCSCs, which was consistent with the earlier observations of the present study. However, after treatment with 740Y-P, the inhibitory effect of curcumin on the proliferation of LCSCs was significantly reversed compared with the cursumin group (Fig. 6A; $\mathrm{P}<0.05$ ). The cell apoptosis of LCSCs was also detected by flow cytometry following treatment with 740Y-P. As shown in Fig. 6B and C, the apoptosis of LCSCs was significantly increased after treatment with curcumin compared with the control group $(\mathrm{P}<0.05)$, but was significantly reversed by treatment with 740Y-P compared with the curcumin group $(\mathrm{P}<0.01)$.

The expression levels of various apoptosis-associated proteins were also detected by western blot assay following treatment with curcumin and/or 740Y-P. As shown in Fig. 7, the expression levels of caspase-3 and caspase-9 were significantly increased upon treatment with curcumin alone compared with the control group $(\mathrm{P}<0.01)$, but were significantly decreased to nearly a normal level after combined treatment with curcumin and 740Y-P compared with the curcumin group (Fig. 7A and $\mathrm{B} ; \mathrm{P}<0.01$ ). In addition, the expression of $\mathrm{Bax}$ was increased and the expression of Bcl-2 was decreased following treatment with curcumin alone. However, upon treatment with curcumin and 740Y-P, the expression of Bax was significantly decreased $(\mathrm{P}<0.05)$ and the expression of Bcl-2 was significantly increased compared with the curcumin group (Fig. 7C and $\mathrm{D} ; \mathrm{P}<0.01$ ). The levels of cytochrome $c$ in the mitochondria and cytoplasm were also detected by western blot analysis. The results revealed that, after treatment with curcumin alone, the levels of cytochrome $c$ in the mitochondria were markedly decreased, whereas the levels of cytochrome $c$ in the cytoplasm were markedly increased. By contrast, subsequent to co-treatment with 740Y-P, the decreased levels of cytochrome $c$ in the mitochondria and increased levels in the cytoplasm were significantly reversed compared with the curcumin group (Fig. 8; $\mathrm{P}<0.01$ and $\mathrm{P}<0.05$, respectively). These results revealed that, upon treatment with the PI3K/AKT activator 740Y-P, the effects of curcumin on LCSCs were reversed.

\section{Discussion}

Liver cancer is a type of malignancy with a strong impact on human health, and LCSCs are important in the recurrence of this tumor. In the present study, the effects of curcumin on the growth of LCSCs were investigated. The results revealed that curcumin inhibited the proliferation and induced apoptosis in LCSCs. Further experiments demonstrated that the $\mathrm{PI} 3 \mathrm{~K} / \mathrm{AKT} / \mathrm{mTOR}$ signaling pathway was involved in the growth-inhibitory effect of curcumin. 


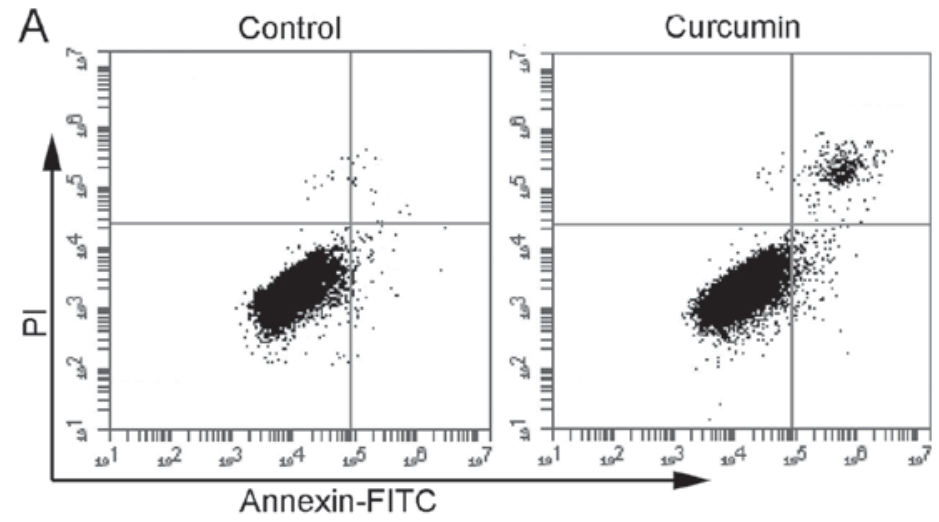

B

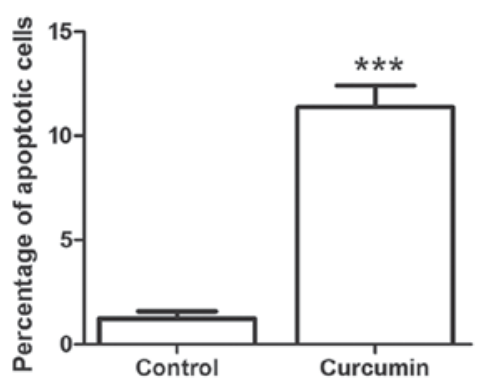

Figure 2. Curcumin promoted the apoptosis of LCSCs. (A) After treatment with $20 \mu \mathrm{M}$ curcumin, the apoptosis of LCSCs was detected by flow cytometry. (B) The percentage of apoptotic cells in each group is shown. All experiments were repeated more than three times and the results are presented as the mean \pm standard deviation. ${ }^{* * * *} \mathrm{P}<0.001$ vs. control group. LCSCs, liver cancer stem cells; FITC, fluorescein isothiocyanate; PI, propidium iodide.
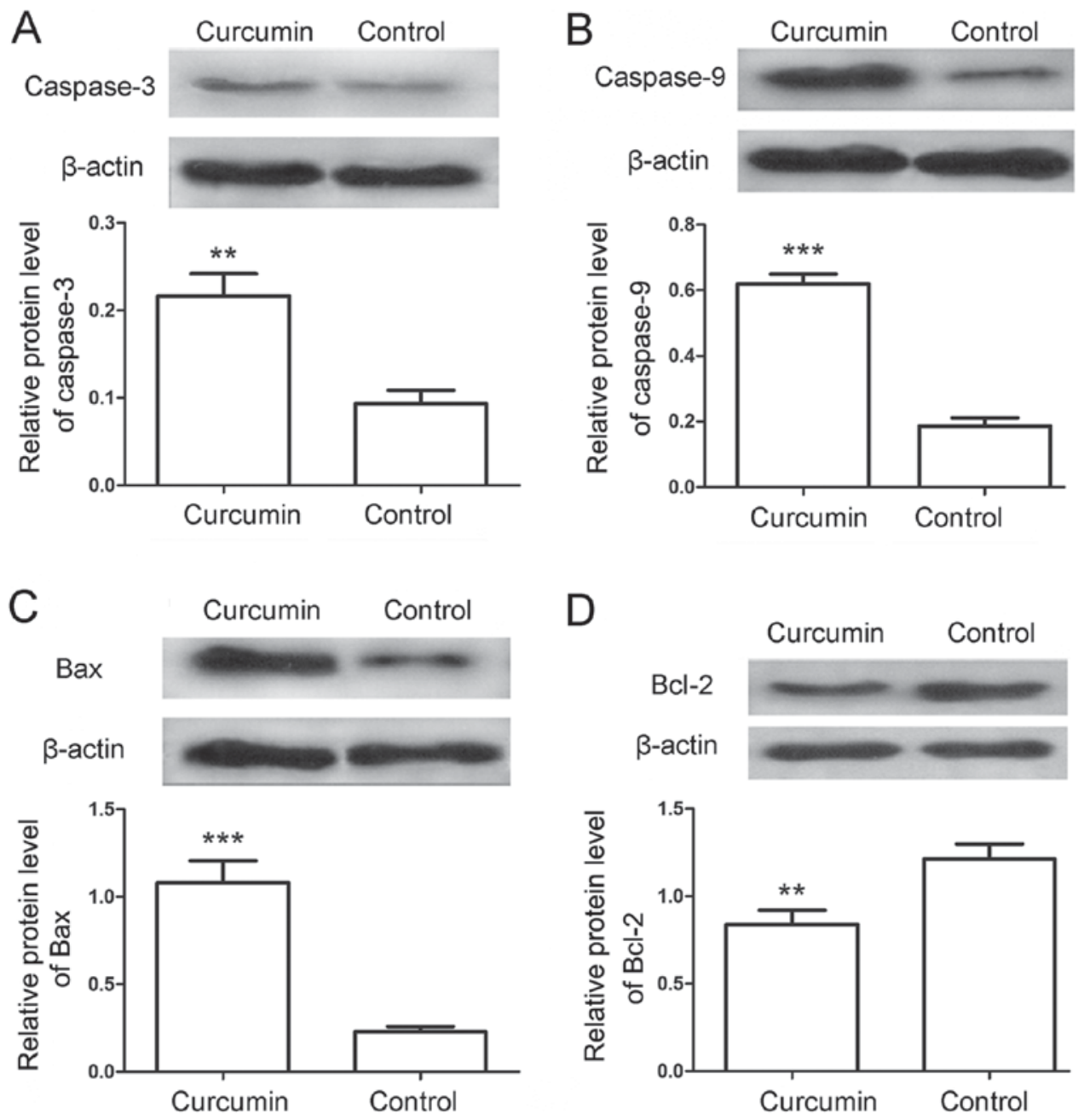

Figure 3. Curcumin regulated the expression of apoptosis-associated proteins. Subsequent to treatment with $20 \mu \mathrm{M}$ curcumin, the protein levels of (A) caspase-3, (B) caspase-9, (C) Bax and (D) Bcl-2were detected by western blot analysis. The relative protein levels were calculated using $\beta$-actin as the internal reference. All experiments were repeated three times. The results are expressed as the mean \pm standard deviation. ${ }^{* *} \mathrm{P}<0.01$ and ${ }^{* * * *} \mathrm{P}<0.001$ vs. control group. Bcl-2, B-cell lymphoma-2; Bax, Bcl-2 associated X protein.

Curcumin has been suggested to ameliorate liver damage induced by various factors (19-22), and to exert an anticancer effect in liver cancer (23-29). In the current study, it was demonstrated that curcumin inhibited the proliferation of
LCSCs. As LCSCs are closely associated with the recurrence of liver cancer, the present study suggests that curcumin may have an excellent anticancer effect, reducing the recurrence of liver cancer. Furthermore, curcumin has been observed to 
A
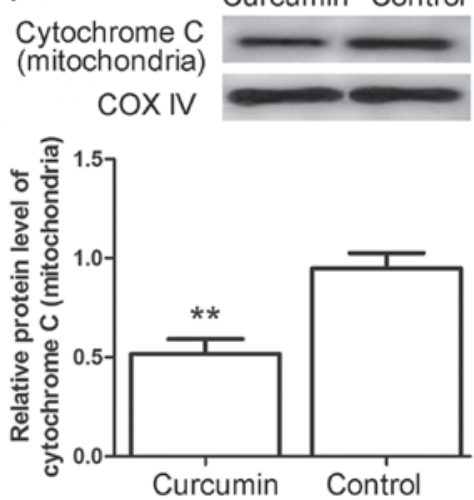

B
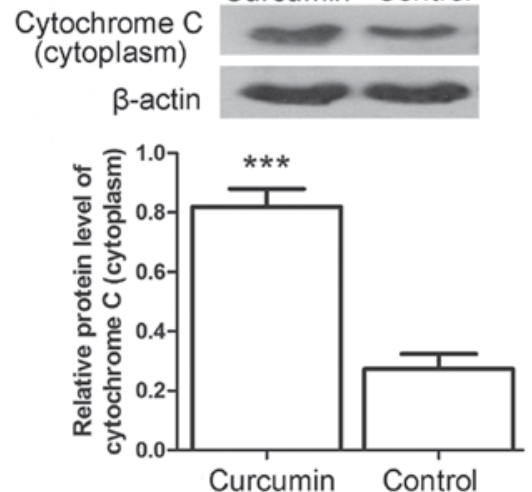

Figure 4. Curcumin inhibited the release of cytochrome $c$. Western blot analysis was used to detect the protein levels of (A) cytochrome $c$ in the mitochondria using COX IV as the internal reference and (B) cytochrome $c$ in the cytoplasm using $\beta$-actin as the internal reference. Each experiment was repeated three times and the results are expressed as the mean \pm standard deviation. ${ }^{* *} \mathrm{P}<0.01$ and ${ }^{* * * *} \mathrm{P}<0.001$ vs. control group. COX IV, cytochrome $c$ oxidase subunit IV.

A

PI3K

$\beta$-actin

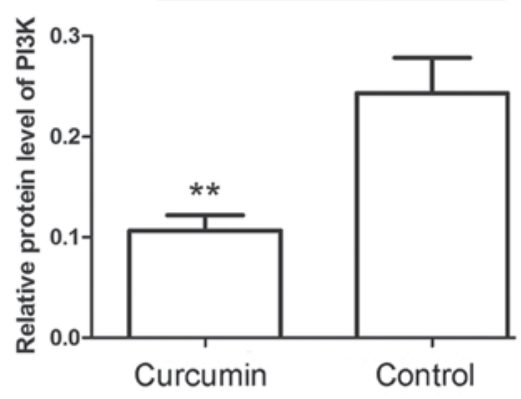

C
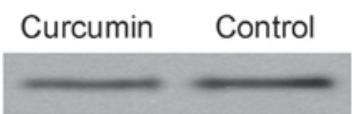

(1)

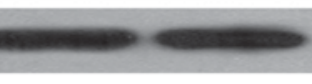

\section{Curcumin Control}

p-mTOR

mTOR

$\beta$-actin

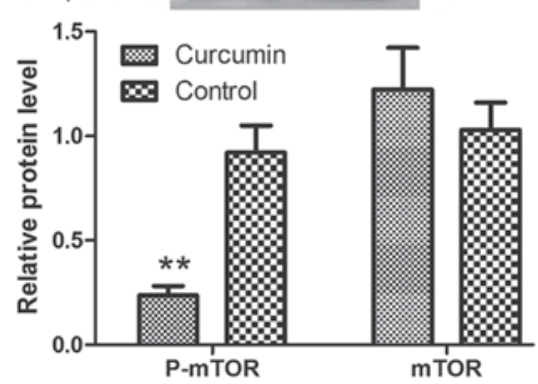

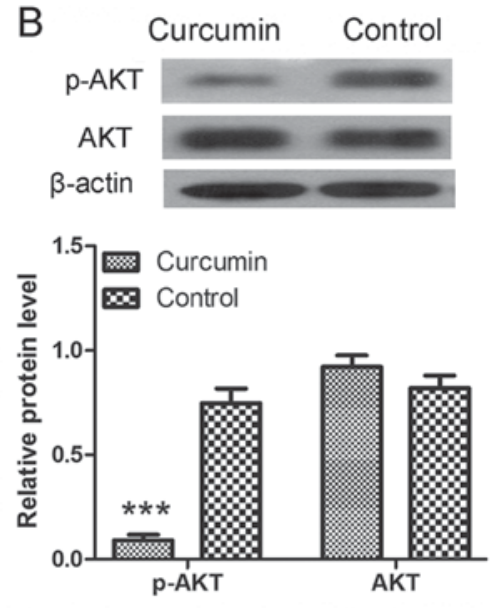

Figure 5. Curcumin inhibited the activation of the PI3K/AKT/mTOR signaling pathway. Following treatment with curcumin, western blot analysis was used to detect the expression levels of (A) PI3K, (B) AKT and p-AKT, and (C) mTOR and p-mTOR. $\beta$-actin was used as the internal reference. All experiments were repeated three times and the results are demonstrated as the mean \pm standard deviation. ${ }^{* *} \mathrm{P}<0.01$ and ${ }^{* * * *} \mathrm{P}<0.001$ vs. control group. PI3K, phosphatidylinositol 3-kinase; AKT, protein kinase B; mTOR, mammalian target of rapamycin; p-, phosphorylated.

exert a potential anticancer effect in multiple cancer types, inhibiting the cancer-associated proliferation, migration and angiogenesis (30-33).

Cancer stem cells are a population of cancer cells with the ability to self-renew, differentiate, as well as initiate and sustain tumor growth. It is considered that cancer stem cells are responsible for cancer recurrence and chemoresistance $(34,35)$. Therefore, agents targeting cancer stem cells may have an improved therapeutic effect in cancer and control tumor recurrence. In the present study, it was observed that curcumin inhibited the growth of LCSCs. Consistent with these findings, curcumin has previously been reported to 

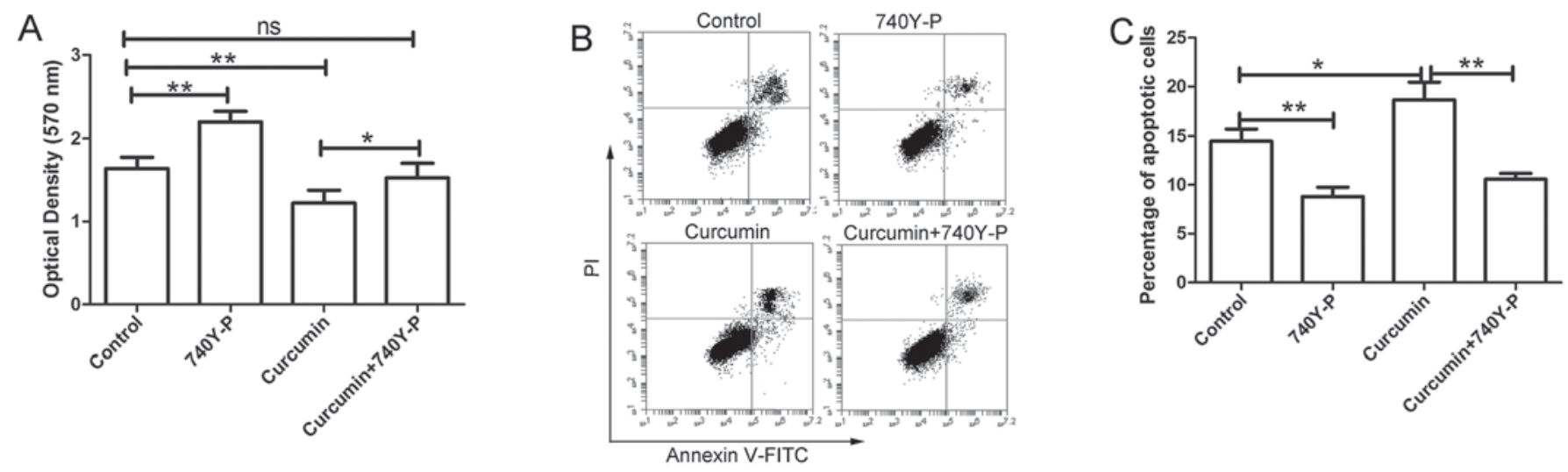

Figure 6. 740Y-P reversed the effects of curcumin on the proliferation and apoptosis of LCSCs. After treatment with curcumin and/or 740Y-P, (A) the proliferation of LCSCs was detected by MTT assay, (B) the apoptosis of LCSCs was detected by flow cytometry, and (C) the percentage of apoptotic cells was calculated. Each experiment was repeated more than three times and the results are demonstrated as the mean \pm standard deviation. ${ }^{*} \mathrm{P}<0.05$ and ${ }^{* *} \mathrm{P}<0.01$. LCSCs, liver cancer stem cells; ns, non-significant; FITC, fluorescein isothiocyanate; PI, propidium iodide.

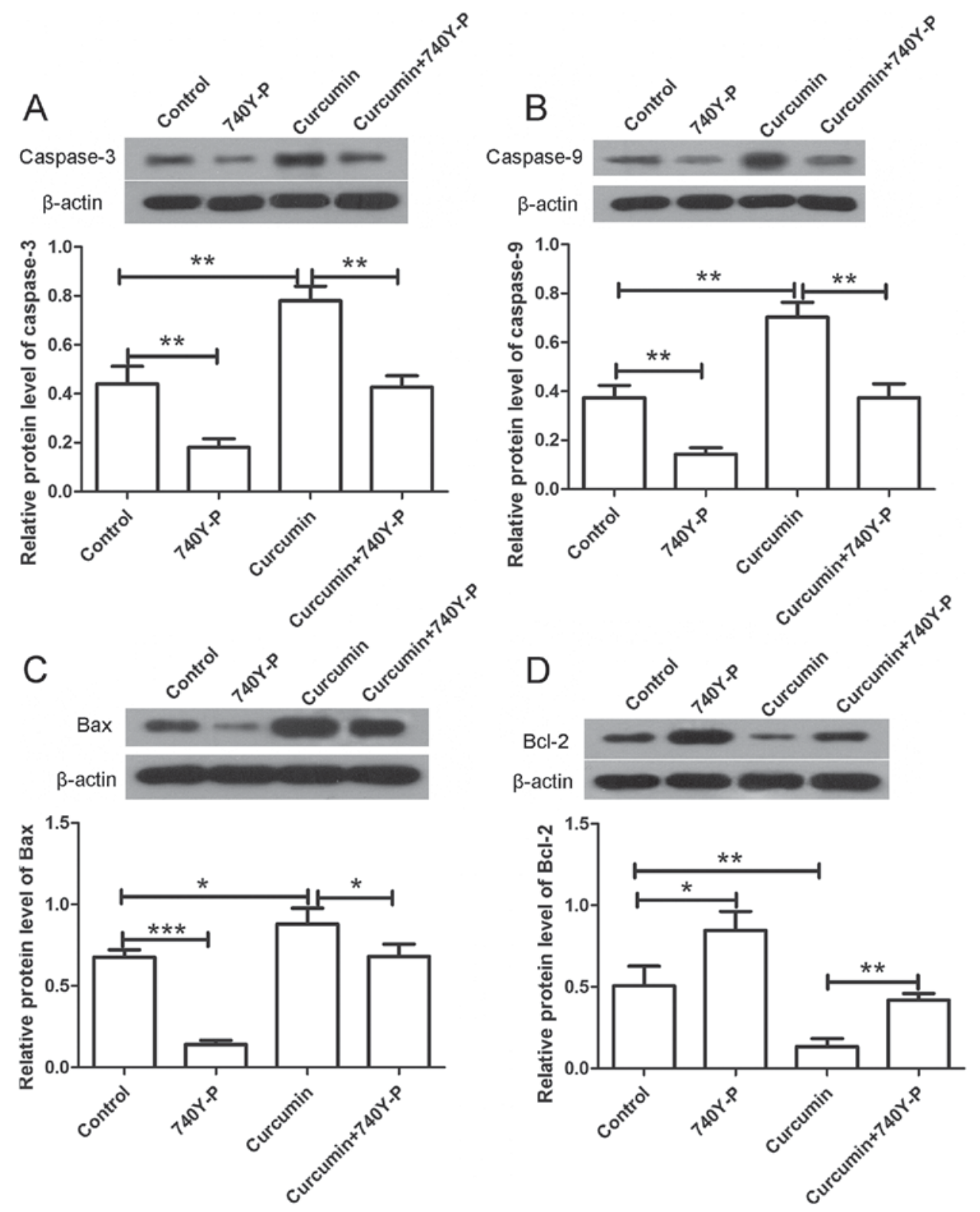

Figure 7. 740Y-P reversed the effects of curcumin on the expression of apoptosis-associated proteins. After treatment with curcumin and/or 740Y-P, the protein levels of (A) caspase-3, (B) caspase-9, (C) Bax and (D) Bcl-2 were detected by western blot analysis. $\beta$-actin was used as the internal reference. All experiments were repeated more than three times. The results are expressed as the mean \pm standard deviation. ${ }^{*} \mathrm{P}<0.05,{ }^{* * *} \mathrm{P}<0.01$ and ${ }^{* * * *} \mathrm{P}<0.001$. Bcl-2, B-cell lymphoma-2; Bax, Bcl-2 associated X protein. 


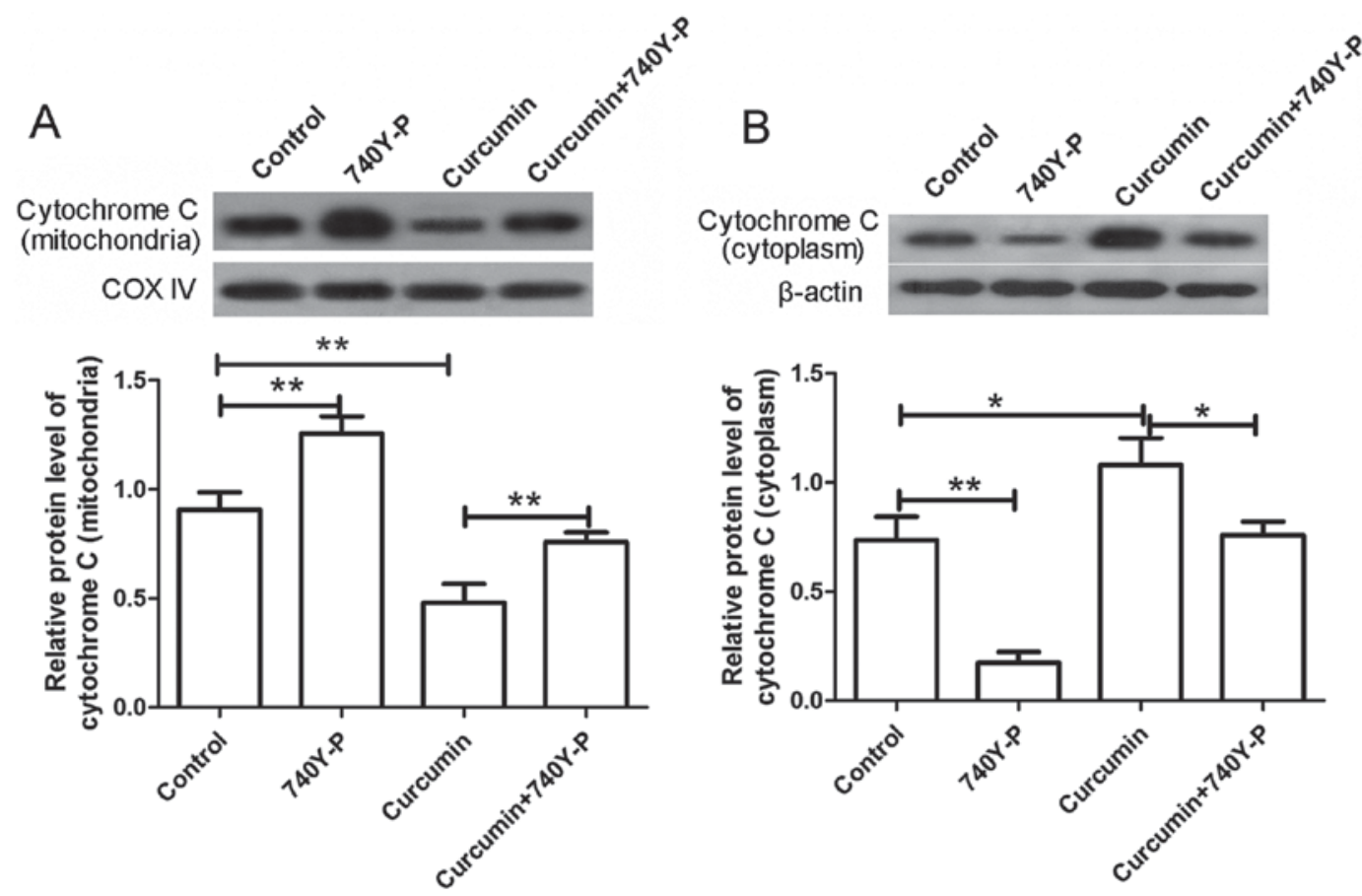

Figure 8. 740Y-P reversed the effects of curcumin on the release of cytochrome $c$. Following treatment with curcumin and/or 740Y-P, western blot analysis was used to detect the protein expression levels of (A) cytochrome $c$ in the mitochondria using COX IV as the internal reference and (B) cytochrome $c$ in the cytoplasm using $\beta$-actin as the internal reference. Each experiment was repeated more than three times. The results are presented as the mean \pm standard deviation. ${ }^{*} \mathrm{P}<0.05$ and ${ }^{* *} \mathrm{P}<0.01$. COX IV, cytochrome $c$ oxidase subunit IV.

inhibit the growth of breast cancer and glioblastoma stem cells $(34,36)$.

Curcumin has chemopreventive and chemotherapeutic effects in cancer, while Phase I and II clinical trials demonstrated that this compound was well-tolerated in cancer patients $(37,38)$. Previous studies revealed that the growth-inhibitory effect of curcumin on cancer cells was linked with its apoptosis-inducing effect $(39,40)$. In the present study, curcumin was identified to induce apoptosis in LCSCs. In addition, the protein levels of apoptosis-associated caspase- 3 and caspase- 9 in LCSCs were also increased, which provided additional evidence for the apoptosis-inducing effect of curcumin. The current study also demonstrated an increased Bax level and decreased Bcl-2 level in LCSCs following treatment with curcumin, further suggesting the apoptosis-inducing effect of curcumin. Furthermore, the ratio of $\mathrm{Bcl}-2 / \mathrm{Bax}$ is known to be associated with the opening of the mitochondrial permeability transition pores, and alterations in mitochondrial membrane potential lead to the release of cytochrome $c(41,42)$. In the present study, release of cytochrome $c$ was also detected following treatment with curcumin. These results indicate that the apoptosis-inducing effect of curcumin may be associated with the mitochondrion-mediated apoptosis. The release of cytochrome $c$ leads to the activation of caspase-9, which is an initiator of cell death (43). The activation of caspase-9, in turn, leads to the cleave of caspase- 3 and then the cleave of poly (ADP-ribose) polymerase 1, which is a nuclear protein associated with programmed cell death (44). Finally, curcumin also affects the cell cycle progression, autophagy, invasion, epithelial-mesenchymal transition, angiogenesis and drug resistance of cancer cells (45-51).
The PI3K/AKT signaling pathway is closely associated with cell growth and is a critical target of chemotherapeutics. In the present study, the results observed that treatment with curcumin inhibited the activation of the PI3K/AKT/mTOR signaling pathway; however, co-treatment with an activator of PI3K/AKT reversed the effects of curcumin. These results demonstrate that curcumin performs its growth-inhibitory effect in LCSCs through the PI3K/AKT/mTOR signaling pathway. Curcumin can also impact the cell cycle progression, autophagy, invasion, epithelial-mesenchymal transition and angiogenesis of cancer cells through the PI3K/AKT signaling pathway, thus inhibiting the growth and metastasis of cancer (45-49). In addition, curcumin exerts an anti-inflammatory effect and protects cardiomyocytes against high glucose-induced apoptosis through this pathway $(9,52)$. Additionally, previous studies demonstrated that the Wnt/ $\beta$-catenin, Notch- 1 , nuclear factor- $\kappa \mathrm{B}$ and mitogen-activated protein kinase signaling pathways were also involved in the effects of curcumin in cancer cells (51,53-57), and these signaling pathways may also be involved in the growth-inhibitory effect of curcumin in LCSCs; however, this requires further investigation in future studies.

In conclusion, the present study demonstrated that curcumin inhibited the growth of LCSCs through the PI3K/AKT/mTOR signaling pathway. These results indicated that curcumin may be an effective anticancer agent in the treatment of liver cancer and may reduce the recurrence of liver cancer.

\section{Acknowledgements}

The authors would like to thank Dr Wei Xi (Jiangsu Cancer Hospital, Nanjing, China) for his assistance in performing the experiments, statistical analysis and manuscript drafting. 


\section{References}

1. Hussain SA, Ferry DR, El-Gazzaz G, Mirza DF, James ND, McMaster P and Kerr DJ: Hepatocellular carcinoma. Ann Oncol 12: 161-172, 2001.

2. Sherman M: Hepatocellular carcinoma: Epidemiology, risk factors, and screening. Semin Liver Dis 25: 143-154, 2005.

3. Bruix J and Sherman M; Practice Guidelines Committee, American Association for the Study of Liver Diseases: Management of hepatocellular carcinoma. Hepatology 42: 1208-1236, 2005.

4. Parkin DM, Bray F, Ferlay J and Pisani P: Global cancer statistics, 2002. CA Cancer J Clin 55: 74-108, 2005.

5. Hu B, Sun D, Sun C, Sun YF, Sun HX, Zhu QF, Yang XR, Gao YB, Tang WG, Fan J, et al: A polymeric nanoparticle formulation of curcumin in combination with sorafenib synergistically inhibits tumor growth and metastasis in an orthotopic model of human hepatocellular carcinoma. Biochem Biophys Res Commun 468: 525-532, 2015.

6. Visvader JE: Cells of origin in cancer. Nature 469: 314-322, 2011.

7. Tork OM, Khaleel EF and Abdelmaqsoud OM: Altered cell to cell communication, autophagy and mitochondrial dysfunction in a model of hepatocellular carcinoma: Potential protective effects of curcumin and stem cell therapy. Asian Pac J Cancer Prev 16: 8271-8279, 2015.

8. Reya T, Morrison SJ, Clarke MF and Weissman IL: Stem cells, cancer, and cancer stem cells. Nature 414: 105-111, 2001.

9. Yu W, Zha W, Ke Z, Min Q, Li C, Sun H and Liu C: Curcumin protects neonatal rat cardiomyocytes against high glucose-induced apoptosis via PI3K/Akt signalling pathway. J Diabetes Res 2016: 4158591, 2016.

10. Seto K, Sakabe T, Itaba N, Azumi J, Oka H, Morimoto M, Umekita Y and Shiota G: A novel small-molecule WNT inhibitor, IC-2, has the potential to suppress liver cancer stem cells. Anticancer Res 37: 3569-3579, 2017.

11. Xiao Y, Lin M, Jiang X, Ye J, Guo T, Shi Y and Bian X: The recent advances on liver cancer stem cells: Biomarkers, separation, and therapy. Anal Cell Pathol (Amst) 2017: 5108653, 2017.

12. Wang R, Sun Q, Wang P, Liu M, Xiong S, Luo J, Huang H, Du Q, Geller DA and Cheng B: Notch and Wnt/ $\beta$-catenin signaling pathway play important roles in activating liver cancer stem cells. Oncotarget 7: 5754-5768, 2016.

13. Sandur SK, Ichikawa H, Pandey MK, Kunnumakkara AB, Sung B, Sethi G and Aggarwal BB: Role of pro-oxidants and antioxidants in the anti-inflammatory and apoptotic effects of curcumin (diferuloylmethane). Free Radic Biol Med 43: 568-580, 2007.

14. Suckow BK and Suckow MA: Lifespan extension by the antioxidant curcumin in Drosophila melanogaster. Int J Biomed Sci 2: 402-405, 2006.

15. Yoysungnoen P, Wirachwong P, Changtam C, Suksamrarn A and Patumraj S: Anti-cancer and anti-angiogenic effects of curcumin and tetrahydrocurcumin on implanted hepatocellular carcinoma in nude mice. World J Gastroenterol 14: 2003-2009, 2008.

16. Masuelli L, Benvenuto M, Fantini M, Marzocchella L, Sacchetti P, Di Stefano E, Tresoldi I, Izzi V, Bernardini R, Palumbo C, et al: Curcumin induces apoptosis in breast cancer cell lines and delays the growth of mammary tumors in neu transgenic mice. J Biol Regul Homeost Agents 27: 105-119, 2013.

17. Zhang CY, Zhang L, Yu HX, Bao JD and Lu RR: Curcumin inhibits the metastasis of K1 papillary thyroid cancer cells via modulating E-cadherin and matrix metalloproteinase-9 expression. Biotechnol Lett 35: 995-1000, 2013.

18. Sun JH, Luo Q, Liu LL and Song GB: Liver cancer stem cell markers: Progression and therapeutic implications. World J Gastroenterol 22: 3547-3557, 2016

19. Afrin R, Arumugam S, Rahman A, Wahed MI,Karuppagounder V Harima M, Suzuki H, Miyashita S, Suzuki K, Yoneyama H, et al: Curcumin ameliorates liver damage and progression of NASH in NASH-HCC mouse model possibly by modulating $\mathrm{HMGB} 1-\mathrm{NF}-\kappa \mathrm{B}$ translocation. Int Immunopharmacol 44: $174-182,2017$.

20. Zhong W, Qian K, Xiong J, Ma K, Wang A and Zou Y: Curcumin alleviates lipopolysaccharide induced sepsis and liver failure by suppression of oxidative stress-related inflammation via PI3K/AKT and $\mathrm{NF}-\kappa \mathrm{B}$ related signaling. Biomed Pharmacother 83: 302-313, 2016.

21. He L, Guo Y, Deng Y, Li C, Zuo C and Peng W: Involvement of protoporphyrin IX accumulation in the pathogenesis of isoniazid/rifampicin-induced liver injury: The prevention of curcumin. Xenobiotica 47: 154-163, 2017.
22. Zabihi NA, Pirro M, Johnston TP and Sahebkar A: Is there a role for curcumin supplementation in the treatment of non-alcoholic fatty liver disease? The data suggest yes. Curr Pharm Des 23: 969-982, 2017.

23. Ellerkamp V, Bortel N, Schmid E,Kirchner B, Armeanu-Ebinger S and Fuchs J: Photodynamic therapy potentiates the effects of curcumin on pediatric epithelial liver tumor cells. Anticancer Res 36: 3363-3372, 2016.

24. Bortel N, Armeanu-Ebinger S, Schmid E, Kirchner B, Frank J, Kocher A, Schiborr C, Warmann S, Fuchs J and Ellerkamp V: Effects of curcumin in pediatric epithelial liver tumors: Inhibition of tumor growth and alpha-fetoprotein in vitro and in vivo involving the NFkappaB- and the beta-catenin pathways. Oncotarget 6: 40680-40691, 2015.

25. Duan W, Chang Y, Li R, Xu Q, Lei J, Yin C, Li T, Wu Y, Ma Q and Li X: Curcumin inhibits hypoxia inducible factor-1 $\alpha$-induced epithelial-mesenchymal transition in HepG2 hepatocellular carcinoma cells. Mol Med Rep 10: 2505-2510, 2014.

26. Chiablaem K, Lirdprapamongkol K, Keeratichamroen S, Surarit R and Svasti J: Curcumin suppresses vasculogenic mimicry capacity of hepatocellular carcinoma cells through STAT3 and PI3K/AKT inhibition. Anticancer Res 34: 1857-1864, 2014.

27. Xu MX, Zhao L, Deng C, Yang L, Wang Y, Guo T, Li L, Lin J and Zhang L: Curcumin suppresses proliferation and induces apoptosis of human hepatocellular carcinoma cells via the wnt signaling pathway. Int J Oncol 43: 1951-1959, 2013.

28. Dai XZ, Yin HT, Sun LF, Hu X, Zhou C, Zhou Y, Zhang W, Huang XE and Li XC: Potential therapeutic efficacy of curcumin in liver cancer. Asian Pac J Cancer Prev 14: 3855-3859, 2013.

29. Kim HJ, Park SY, Park OJ and Kim YM: Curcumin suppresses migration and proliferation of Hep3B hepatocarcinoma cells through inhibition of the Wnt signaling pathway. Mol Med Rep 8: 282-286, 2013

30. Sa G and Das T: Anti cancer effects of curcumin: Cycle of life and death. Cell Div 3: 14, 2008.

31. Yang CL, Liu YY, Ma YG, Xue YX, Liu DG, Ren Y, Liu XB, Li Y and Li Z: Curcumin blocks small cell lung cancer cells migration, invasion, angiogenesis, cell cycle and neoplasia through Janus kinase-STAT3 signalling pathway. PLoS One 7: e37960, 2012.

32. Sinha D, Biswas J, Sung B, Aggarwal BB and Bishayee A: Chemopreventive and chemotherapeutic potential of curcumin in breast cancer. Curr Drug Targets 13: 1799-1819, 2012.

33. Bhandarkar SS and Arbiser JL: Curcumin as an inhibitor of angiogenesis. Adv Exp Med Biol 595: 185-195, 2007.

34. Dandawate PR, Subramaniam D, Jensen RA and Anant S: Targeting cancer stem cells and signaling pathways by phytochemicals: Novel approach for breast cancer therapy. Semin Cancer Biol 40-41: 192-208, 2016.

35. Subramaniam D, Kaushik G, Dandawate P and Anant S: Targeting cancer stem cells for chemoprevention of pancreatic cancer. Curr Med Chem: Jan 26, 2017 (Epub ahead of print).

36. Gersey ZC, Rodriguez GA, Barbarite E, Sanchez A, Walters WM, Ohaeto KC, Komotar RJ and Graham RM: Curcumin decreases malignant characteristics of glioblastoma stem cells via induction of reactive oxygen species. BMC Cancer 17: 99, 2017.

37. Cheng AL, Hsu CH, Lin JK, Hsu MM, Ho YF, Shen TS, Ko JY, Lin JT, Lin BR, Ming-Shiang W, et al: Phase I clinical trial of curcumin, a chemopreventive agent, in patients with high-risk or pre-malignant lesions. Anticancer Res 21: 2895-2900, 2001.

38. Dhillon N, Aggarwal BB, Newman RA, Wolff RA, Kunnumakkara AB, Abbruzzese JL, Ng CS, Badmaev V and Kurzrock R: Phase II trial of curcumin in patients with advanced pancreatic cancer. Clin Cancer Res 14: 4491-4499, 2008.

39. Aggarwal BB, Kumar A and Bharti AC: Anticancer potential of curcumin: Preclinical and clinical studies. Anticancer Res 23: 363-398, 2003.

40. Ravindran J, Prasad S and Aggarwal BB: Curcumin and cancer cells: How many ways can curry kill tumor cells selectively? AAPS J 11: 495-510, 2009.

41. Bagci EZ, Vodovotz Y, Billiar TR, Ermentrout GB and Bahar I: Bistability in apoptosis: Roles of bax, bcl-2, and mitochondrial permeability transition pores. Biophys J 90: 1546-1559, 2006.

42. Eissing T, Waldherr S, Allgöwer F, Scheurich P and Bullinger E: Response to bistability in apoptosis: Roles of bax, bcl-2, and mitochondrial permeability transition pores. Biophys J 92: 3332-3334, 2007.

43. Estaquier J, Vallette F, Vayssiere JL and Mignotte B: The mitochondrial pathways of apoptosis. Adv Exp Med Biol 942: 157-183, 2012. 
44. Wurstle ML, Laussmann MA and Rehm M: The central role of initiator caspase-9 in apoptosis signal transduction and the regulation of its activation and activity on the apoptosome. Exp Cell Res 318: 1213-1220, 2012.

45. Zhang Y, Kong Y, Liu S, Zeng L, Wan L and Zhang Z: Curcumin induces apoptosis in human leukemic cell lines through an IFIT2-dependent pathway. Cancer Biol Ther 18: 43-50, 2017.

46. Wang C, Zhang X, Teng Z, Zhang T and Li Y: Downregulation of PI3K/Akt/mTOR signaling pathway in curcumin-induced autophagy in APP/PS1 double transgenic mice. Eur J Pharmacol 740: 312-320, 2014.

47. Xu X, Qin J and Liu W: Curcumin inhibits the invasion of thyroid cancer cells via down-regulation of PI3K/Akt signaling pathway. Gene 546: 226-232, 2014

48. Chen WC, Lai YA, Lin YC, Ma JW, Huang LF, Yang NS, Ho CT, Kuo SC and Way TD: Curcumin suppresses doxorubicin-induced epithelial-mesenchymal transition via the inhibition of TGF- $\beta$ and PI3K/AKT signaling pathways in triple-negative breast cancer cells. J Agric Food Chem 61: 11817-11824, 2013.

49. Jiao D, Wang J, Lu W, Tang X, Chen J, Mou H and Chen QY: Curcumin inhibited HGF-induced EMT and angiogenesis through regulating c-Met dependent $\mathrm{PI} 3 \mathrm{~K} / \mathrm{Akt} / \mathrm{mTOR}$ signaling pathways in lung cancer. Mol Ther Oncolytics 3: 16018,2016

50. Lopes-Rodrigues V, Oliveira A, Correia-da-Silva M, Pinto M, Lima RT, Sousa E and Vasconcelos MH: A novel curcumin derivative which inhibits $\mathrm{P}$-glycoprotein, arrests cell cycle and induces apoptosis in multidrug resistance cells. Bioorg Med Chem 25: 581-596, 2017.

51. Kang Y, Hu W, Bai E, Zheng H, Liu Z, Wu J, Jin R, Zhao C and Liang G: Curcumin sensitizes human gastric cancer cells to 5-fluorouracil through inhibition of the NFKB survival-signaling pathway. Onco Targets Ther 9: 7373-7384, 2016.
52. Cianciulli A, Calvello R, Porro C, Trotta T, Salvatore R and Panaro MA: PI3k/Akt signalling pathway plays a crucial role in the anti-inflammatory effects of curcumin in LPS-activated microglia. Int Immunopharmacol 36: 282-290, 2016.

53. Zheng R, Deng Q, Liu Y and Zhao P: Curcumin inhibits gastric carcinoma cell growth and induces apoptosis by suppressing the Wnt $/ \beta$-catenin signaling pathway. Med Sci Monit 23: 163-171, 2017.

54. Prasad CP, Rath G, Mathur S, Bhatnagar D and Ralhan R: Potent growth suppressive activity of curcumin in human breast cancer cells: Modulation of Wnt/ $\beta$-catenin signaling. Chem Biol Interact 181: 263-271, 2009.

55. Yang J, Wang C, Zhang Z, Chen X, Jia Y, Wang B and Kong T: Curcumin inhibits the survival and metastasis of prostate cancer cells via the Notch-1 signaling pathway. APMIS 125: 134-140, 2017.

56. Tong W, Wang Q, Sun D and Suo J: Curcumin suppresses colon cancer cell invasion via AMPK-induced inhibition of NF- $\kappa \mathrm{B}$, uPA activator and MMP9. Oncol Lett 12: 4139-4146, 2016.

57. Dai C, Lei L, Li B, Lin Y, Xiao X and Tang S: Involvement of the activation of Nrf2/HO-1, p38 MAPK signaling pathways and endoplasmic reticulum stress in furazolidone induced cytotoxicity and S phase arrest in human hepatocyte L02 cells: Modulation of curcumin. Toxicol Mech Methods 27: 165-172, 2017. 